\title{
SCIENTIFIC REPORTS

\section{OPEN Effects of Photodynamic Therapy with Redaporfin on Tumor Oxygenation and Blood Flow in a Lung Cancer Mouse Model}

Received: 13 March 2019

Accepted: 8 August 2019

Published online: 02 September 2019

\begin{abstract}
Malwina Karwicka ${ }^{1}$, Barbara Pucelik ${ }^{2,3}$, Michał Gonet ${ }^{1}$, Martyna Elas ${ }^{1}$ \& Janusz M. Dąbrowski $\mathbb{D}^{2}$
Three photodynamic therapy (PDT) protocols with $15 \mathrm{~min}, 3 \mathrm{~h}$ and $72 \mathrm{~h}$ drug-to-light time intervals (DLIs) were performed using a bacteriochlorin named redaporfin, as a photosensitizer. Blood flow and $\mathrm{pO}_{2}$ changes after applying these protocols were investigated in a Lewis lung carcinoma (LLC) mouse model and correlated with long-term tumor responses. In addition, cellular uptake, cytotoxicity and photocytotoxicity of redaporfin in LLC cells were evaluated. Our in vitro tests revealed negligible cytotoxicity, significant cellular uptake, generation of singlet oxygen, superoxide ion and hydroxyl radicals in the cells and changes in the mechanism of cell death as a function of the light dose. Results of in vivo studies showed that treatment focused on vascular destruction (V-PDT) leads to a highly effective long-term antineoplastic response mediated by a strong deprivation of blood supply. Tumors in $67 \%$ of the LLC bearing mice treated with V-PDT regressed completely and did not reappear for over 1 year. This significant efficacy can be attributed to photosensitizer (PS) properties as well as distribution and accurate control of oxygen level and density of vessels before and after PDT. V-PDT has a greater potential for success than treatment based on longer DLIs as usually applied in clinical practice.
\end{abstract}

Lung cancer is one of the most common types of malignant tumor worldwide and the leading cause of cancer-related deaths. Despite many improvements in disease diagnosis and management, chemotherapy is still the mainstay of treatment for both non-small cell lung cancer (NSCLC) and small cell lung cancer (SCLC). However, chemotherapy resistance can limit the ability to effectively treat advanced lung cancer ${ }^{1,2}$. New anticancer strategies are urgently needed to improve therapeutic success of lung cancer treatments beyond conventional chemotherapeutic drug outcomes.

Photodynamic therapy (PDT) is recognized in clinical practice and holds considerable promise for many solid tumors, including lung cancer ${ }^{3}$. PDT employs reactive oxygen species (ROS) generation according to two main photochemical processes (type I: photo-induced electron transfer with generation of oxygen-centered radicals and type II: energy transfer with singlet oxygen production $)^{4-6}$. ROS are involved in the oxidation of biological structures, leading to oxidative stress and consequently to: (i) apoptosis, necrosis and/or autophagy, (ii) closure of tumor blood vessels ${ }^{7}$, (iii) stimulation of the immune system to local and systemic immune responses ${ }^{8,9}$. The contribution of each mechanisms and the final therapeutic efficacy depend on the dose and structure of the photosensitizer (PS), the therapeutic protocols used and the time intervals from the administration of PS to irradiation (drug-to-light intervals; DLIs), radiation power and oxygen concentration in the tumor ${ }^{4,10-13}$. Results from several in vivo studies performed using lung cancer models indicate variable tumor responses to PDT. Korbelik and colleagues showed that activation of the complement system by Photofrin-PDT in a Lewis lung carcinoma (LLC) tumor model appears to reflect the natural response of innate immunity engaging to maintain homeostasis following acute tumor injury ${ }^{14}$. The antitumor effect of PDT against LLC in in vivo models can be potentiated by 5-aza-dC ${ }^{15}$. Moreover, PDT with 5-aminolevulinic acid (ALA-PDT) decreased metastasis of cancer cells in vivo ${ }^{16}$. Application of ALA-PDT lowered the rate of metastatic spreading, decreased vascular endothelial growth factor

\footnotetext{
${ }^{1}$ Jagiellonian University, Faculty of Biochemistry, Biophysics and Biotechnology, Gronostajowa 7, 30-387, Kraków,

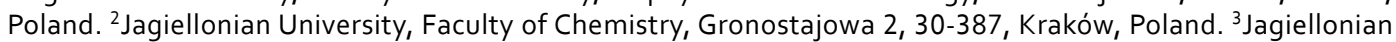
University, Małopolska Centre of Biotechnology, Gronostajowa 7A, 30-387, Kraków, Poland. Malwina Karwicka and Barbara Pucelik contributed equally. Correspondence and requests for materials should be addressed to J.M.D. (email: jdabrows@chemia.uj.edu.pl)
} 
(VEGF) levels in blood serum of LLC bearing mice, and resulted in morphologic alterations of vascular system in tumor tissue. Recently, Allison and colleagues described the mechanisms of PDT action with different photosensitizers (PS) and light sources in the treatment of many tumors including lung cancer ${ }^{17}$. Loewen et al. reviewed the use of Photofrin and HPPH (2-[1-hexyloxyethyl]-2 devinyl pyropheophorbide) in treatment of early-stage lung cancer and reported clinical results. PDT with HPPH led to the delayed cellular effects within tumor and thus was indicated for the palliation of endobronchial lung cancers ${ }^{18}$.

Many treatment failures observed after therapy may be attributed to intrinsic tumor resistance. Tumor hypoxia may be a potential contributing factor to treatment resistance and its impact on tumor vasculature - also highlighted as an important target for $\mathrm{PDT}^{19}$. Recently, the importance of monitoring and non-invasive visualization of tumor blood microvasculature in real time was indicated in photodynamic treatment mediated by chlorine e6 and Photoditazin-based photosensitizer ${ }^{20}$. It has been reported that PDT induces hypoxia and expression of VEGF $^{21}$ via the HIF-1 $\alpha$ pathway ${ }^{22-24}$. Hypoxia is found in $50-60 \%$ of locally advanced solid tumors and is associated with poor clinical outcomes ${ }^{25,26}$. Normal physiological oxygen partial pressure $\left(\mathrm{pO}_{2}\right)$ varies among different tissues, but is usually measured at approximately $43 \mathrm{mmHg}$. Tumor $\mathrm{pO}_{2}$ is a critical factor related to negative effects on cellular functionality depending on corresponding normal tissue $\mathrm{pO}_{2}$ and is proposed to range between approximately $8-10 \mathrm{mmHg}$ in most tumors. However, the critical $\mathrm{pO}_{2}$ threshold associated with treatment resistance may vary with therapeutic schemes ${ }^{25}$. Although a satisfactory effect in treating superficial tumors may be obtained, PDT efficacy in a hypoxic environment is still impaired. PDT increases hypoxia via oxygen consumption and vascular shutdown effects. Low oxygen content in a tumor can reduce phototoxicity, preventing PDT from achieving its full therapeutic potential ${ }^{27}$. The efficacy of ${ }^{1} \mathrm{O}_{2}$ generation is fundamentally dependent on $\mathrm{O}_{2}$ concentration, thus low $\mathrm{O}_{2}$ levels would hamper PDT treatment with a PS that generates mainly ${ }^{1} \mathrm{O}_{2}$. Complete death of radiation-induced fibrosarcoma (RIF) cells after a photodynamic effect mediated by Photofrin appears to be achieved at levels of normal tissue oxygenation with no increase in effectiveness at higher $\mathrm{O}_{2}$ concentrations ${ }^{28}$. Furthermore, lowering $\mathrm{O}_{2}$ levels below $5 \%$ appears to progressively limit cellular photodamage with a half-value of about $1 \%$ (i.e. appr. $7 \mathrm{mmHg}$ ). Traditional methods have attempted to optimize tumor oxygenation to maximize PDT efficacy.

Current understanding of the techniques that can effectively reverse tumor oxygen content during PDT is limited. Therefore, optimizing treatment efficacy under limited oxygen conditions is of great importance for PDT. Tong, X. et al. performed dynamic PET using hypoxic specific tracer ${ }^{18} \mathrm{~F}-\mathrm{FMISO}$ combined with pharmacokinetics modeling. Their research provided the information of hypoxia status during PDT in two tumor xenograft models (U87MG and MDA-MB-435) and indicate that this approach offers a potential imaging tool to characterize tumor hypoxia during treatment ${ }^{29}$. Y. Cheng et al. reported a novel method of "oxygen self-enriching PDT" to enhance the ${ }^{1} \mathrm{O}_{2}$ generation of an applied $\mathrm{PS}^{30}$. Although the tumor oxygen content remained limited during PDT, sufficient $\mathrm{O}_{2}$ was made available for photodynamic consumption by the loaded PS, resulting in improved efficacy. This type of enhancement is possible regardless of pre-existing hypoxia, photodynamic consumption, or vascular damage. Moreover, ${ }^{1} \mathrm{O}_{2}$ lifetime in perfluorocarbon nanodroplets (PFC) is longer than in a cellular environment or in water, which results in long-lasting photodynamic effects ${ }^{27}$. Tumor tissue oxygenation levels are even more crucial after PDT treatment as they influence overall therapeutic outcome. We have shown that redaporfin-PDT induced mild and transient hypoxia with a drug-to-light time interval (DLI) of $72 \mathrm{~h}$ and led to intense $\mathrm{pO}_{2}$ compensatory effects and modest tumor inhibition in a S91 melanoma model ${ }^{31}$. In contrast, strong and persistent local hypoxia after vascular-targeted PDT $(\mathrm{V}-\mathrm{PDT}$; DLI $=15 \mathrm{~min}$ ) caused tumor growth inhibition and led to long-term survival. Non-invasive molecular imaging approaches targeting hypoxia are still being developed and have shown some early success in preclinical and clinical settings ${ }^{32-35}$. These methods also provide staging information and can be useful for monitoring behavior and tumor response in vivo ${ }^{36-38}$.

Many of innovative nanoparticle-based photosensitizers developed recently (e.g. nanoformulation by coating nanoclusters of SPIONs with the photosensitizer Ce6) are also able to serve as effective dual-mode agents for theranostics and photodynamic therapy of murine tumor model ${ }^{39-42}$. Small animal Electron Paramagnetic Resonance (EPR) imaging modalities have been applied e.g. in time-domain mode and EPR imaging is used routinely in mouse models of tumor to map tumor hypoxia ${ }^{43}$. As mentioned above, the importance of mapping out tumor hypoxia stems from the fact that hypoxic tumor cells are about 3-4 times more resistant to various types of treatments than normal cells. Thus, mapping of tumor hypoxia aids in the planning of therapeutic procedures and improves prognosis of treatment ${ }^{44,45}$. To address this challenge, our study employed three-dimensional imaging using EPR oximetry to assess tumor response to PDT with redaporfin as a PS. Redaporfin is currently in phase II clinical trials for advanced head and neck tumors. The phototoxicity of this PS is mediated by both type I and type II photochemical mechanisms, so it can efficiently generate singlet oxygen as well as oxygen-centered radicals after irradiation with near-infrared radiation (NIR) light. Previously, we demonstrated the superior efficacy of redaporfin as a PS in multiple tumor models $s^{4,46,47}$, including highly aggressive pigmented melanoma ${ }^{48}$.

Herein, we performed in vivo PDT on LLC tumors growing in syngeneic C57BL/6J mice. LLC was selected for the tumor model as it is considered highly malignant, life-threatening, and one of the most difficult cancers to treat $^{49}$. An advantage of the LLC model is that implanted cells are immunologically compatible with the murine system, unlike widely used xenograft models in which human cells are implanted into mouse tissue. The LLC model can be created on an immunocompetent murine background, such as C57BL, and true immune and toxicity responses can be evaluated with respect to targeted therapies and tumor growth ${ }^{50,51}$. Current study found that a single dose of redaporfin and irradiation with NIR light at a dose of $105 \mathrm{~J} / \mathrm{cm}^{2}$ can effectively inhibit LLC tumor growth. It has been demonstrated that redaporfin can accumulate in tumor tissue at $15 \mathrm{~min}$ after intravenous (i.v.) injection of PS. Additionally, we assessed intracellular hypoxia in tumor tissue by a non-invasive EPR oximetry technique using a paramagnetic probe. This approach uniquely allows for measuring changes in tumor tissue $\mathrm{pO}_{2}$ and reperfusion in LLC tumor models. Moreover, we have studied the level of oxygen in LLC tumors using 


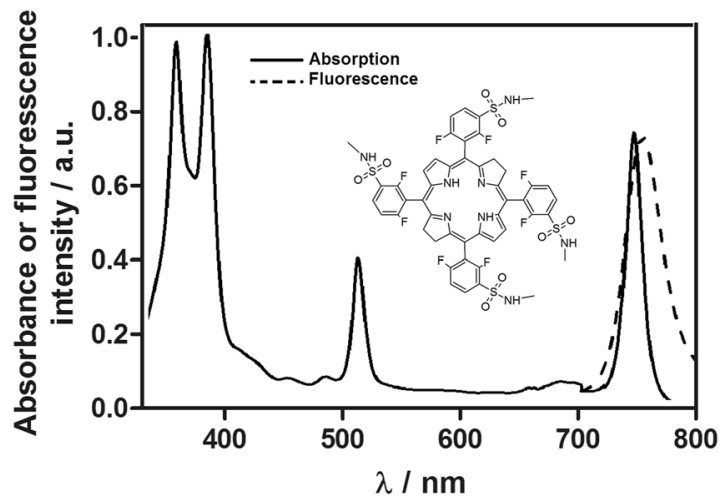

Figure 1. Electronic absorption and fluorescence spectra of redaporfin and its molecular structure (inset).

pimonidazole hydrochloride as an immunohistochemical marker for hypoxia and correlated tissue oxygenation, tumor vasculature, and blood flow with overall therapeutic efficacy after redaporfin-PDT.

\section{Results}

The in vitro studies of redaporfin activity against LLC cells. Redaporfin readily absorbs NIR light (Fig. 1) in the middle of the phototherapeutic window where endogenous pigments do not absorb light, photons are non-toxic and their energy is still sufficient for photochemical reactions such as an energy transfer to molecular oxygen.

In order to determine the photodynamic efficacy of $\mathrm{F}_{2} \mathrm{BMet}$, in the first part of the study, the biological activity in vitro was analyzed. Firstly, we investigated the time-dependent cellular uptake of redaporfin by LLC cells exposing the cells to redaporfin at concentration of $5 \mu \mathrm{M}$. As shown in Fig. 2a, the cellular uptake attains its maximum after $24 \mathrm{~h}$ of incubation and it is comparable to that performed on other cell lines ${ }^{31}$. The photoxicity in the dark towards LLC cells was tested with various incubation times. Incubation of the cells for $24 \mathrm{~h}$ with redaporfin in the range of concentrations tested $(0.1-100 \mu \mathrm{M})$ did not reveal significant cytotoxicity up to dose of $20 \mu \mathrm{M}$ (Fig. $2 \mathrm{~b}$ ).

It is well-known that cell death triggered by photodynamic therapy occurs through various mechanisms, including apoptosis, necrosis, autophagy and others ${ }^{52}$. Upon irradiation of LLC cells with the light dose of $0.15 \mathrm{~J} / \mathrm{cm}^{2}$ $(\lambda=735 \pm 20 \mathrm{~nm})$, redaporfin generates ROS that consequently lead to cell destruction and significant cell killing (>80\%) (Fig. 2c). Cell death mechanism was further examined by flow cytometry using Annexin V-FITC and PI staining, Fig. 2e. It was observed that redaporfin-mediated photodynamic effect against LLC cells with high light dose $\left(10 \mathrm{~J} / \mathrm{cm}^{2}\right)$ caused necrosis, while smaller doses $\left(1 \mathrm{~J} / \mathrm{cm}^{2}\right)$ initiated apoptosis. It was revealed that irradiation of redaporfin-photosensitized cells led to an increase in the number of cells that expressed phosphatidilserine from the inner space of the plasma membrane to the cell surface combined with Annexin V-FITC (68.9\% stained (Q3) vs. 2.31\% non-stained, lived cells (Q4)). Furthermore, increasing the light dose led to a significant increase in Annexin V-PI double-positive and PI-positive cells, which suggested a decrease in the integrity of the cell membrane and switch to preferred necrotic cell death (77.6\% stained cells (Q2) vs. 1.09\% non-stained cells (Q4)). Redaporfin belongs to the group of compounds generating both singlet oxygen and oxygen-centered radicals. Nevertheless, the participation of photosensitizing mechanisms is dependent on the oxygen concentration in the reaction environment. The intracellular ROS generation by redaporfin in LLC cells was examined using SOSG probe selective for singlet oxygen production, APF and HPF specific for hydroxyl radicals and DHE for superoxide anion identification. All of applied probes are non-fluorescent, but their oxidized by ROS products emit a specific fluorescence. The non-irradiated cells did not show any fluorescein emission. As illustrated in Fig. 2d, during irradiation LLC cells, the singlet oxygen is produced in large amount what may indicate that the II type of reaction is more favorable mechanism of ROS generation in well oxygenated cellular environment. However, radicals such as the $\mathrm{O}_{2}{ }^{-}$and $\mathrm{HO}^{\circ}$, are most likely involved in the cell damage. Type I reactions triggered by redaporfin add to the Type II reaction initiated by singlet oxygen, which will have implications in in vivo conditions, where other factors such as hypoxia, blood flow, level of vascularization have to be taken into account.

In vivo tissue distribution of redaporfin is dependent on DLI - a case study. The experiments described in this section are focused on LLC tumor response and vascular effects after redaporfin-PDT. PDT can be designed to target either tumor vasculature, tumor cells, or both depending on PS properties ${ }^{53}$, formulation, and the DLI ${ }^{54-56}$ properly designed in order to increase therapeutic response. Tissue distribution of redaporfin in tumor, blood, and other organs were examined by fluorescence measurements of tissue extracts collected at $15 \mathrm{~min}, 3 \mathrm{~h}$ and $72 \mathrm{~h}$ after PS administration and results are presented in Fig. 3.

During the first 15 min post-injection, a higher amount of PS is found in blood and tumor than after 3 or $72 \mathrm{~h}$. PS concentration increases in spleen, liver and intestines over time. Likewise after 72 hours the highest level of PS was identified in these organs, namely in the liver, spleen and intestines, respectively. This suggests that the main route of its elimination seems to be intestines. The biodistribution results are in good agreement with our previous studies performed on CT26 $6^{4,46}$. A similar tissue distribution of redaporfin formulated with CrEL, was recently found in the same mouse model (C57BL/6J) bearing pigmented B16 melanoma ${ }^{48}$ as well as S91-bearing DBA/2 
(a)

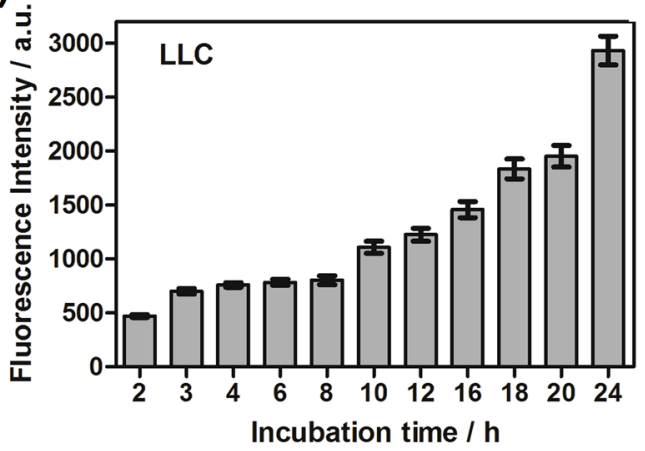

(c)

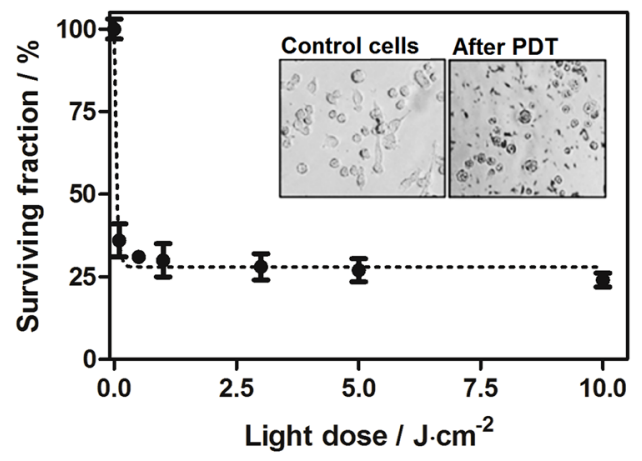

(b)

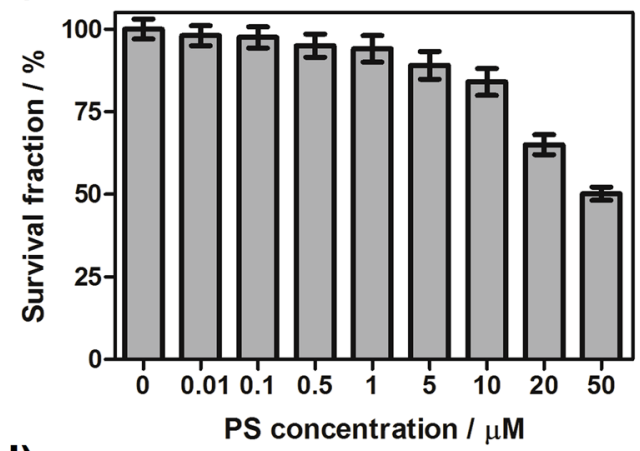

(d)

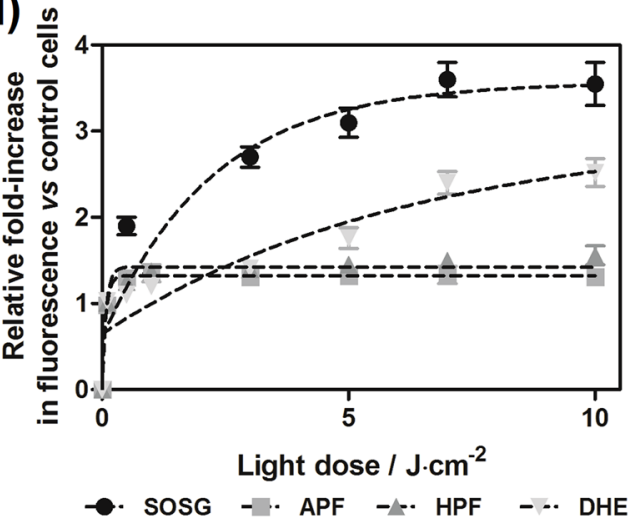

(e)
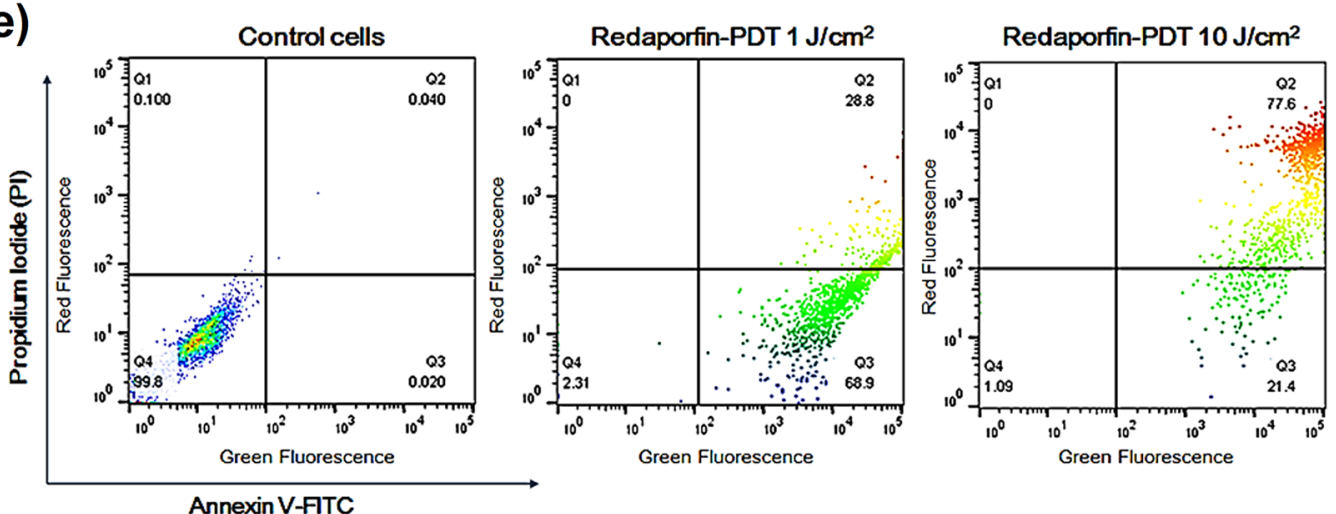

Annexin V-FTC

Figure 2. In vitro evaluation of redaporfin efficacy in LLC cells: (a) time-dependent cellular uptake of redaporfin in LLC cells; (b) cytotoxicity in the dark induced by redaporfin in a wide-range of applied concentrations; (c) redaporfin-mediated photodynamic effect against LLC cells performed after $3 \mathrm{~h}$ incubation and irradiation with various light doses, inset shows morphology of cells before and after treatment; (d) photogeneration of ROS in LLC cells: fluorescence generated from ROS probes: APF, HPF, SOSG and DHE in LLC cells incubated with redaporfin for $3 \mathrm{~h}$ and irradiated with NIR light; (e) determination of cell death mechanism induced by photodynamic effect: the Annexin V-FITC/propidium iodide (PI) double staining assay (Annexin V-FITC in green fluorescence and PI in red fluorescence) was used to detect phosphatidylserine externalization in apoptosis and analyze the membrane integrity: non-treated control LLC cells (left), LLC cells treated with redaporfin-PDT with light dose at $1 \mathrm{~J} / \mathrm{cm}^{2}$ (middle) and $10 \mathrm{~J} / \mathrm{cm}^{2}$ (right).

mice ${ }^{31,57,58}$ although the comparison must take into account varied vascularization of these models and different mode of administration employed. The biodistribution of redaporfin in C57BL/6J mice bearing LLC tumors also revealed that tumor-to-muscle (T:M) and tumor-to-skin (T:S) ratios achieved reasonable values already $15 \mathrm{~min}$ after i.v. injection of PS (Table 1).

In accordance with biodistribution studies, PDT efficacy with redaporfin was assessed in the same animal and tumor models, C57BL/6J mice bearing LLC, which were treated with a single dose of light at $15 \mathrm{~min}$ (V-PDT), $3 \mathrm{~h}$ (E-PDT) and $72 \mathrm{~h}$ (C-PDT) after i.v. injection of PS. Irradiation was carried out for $13.5 \mathrm{~min}$, at a light dose of $105 \mathrm{~J} / \mathrm{cm}^{2}$ using a $130 \mathrm{~mW}$ laser at $749 \mathrm{~nm}$ within the optimal safety margin for normal tissue. In order to evaluate tumor response related to the selected PDT protocols, the kinetics of tumor growth were investigated. Various acute reactions including edema, erythema, and scab formation were also noted after PDT. Local tumor responses after V-PDT and E-PDT differed. Edema appeared immediately after V-PDT treatment in contrast to a less acute 


\begin{tabular}{|l|l|l|l|}
\hline & $\mathbf{D L I}=\mathbf{1 5} \mathbf{~ m i n}$ & $\mathbf{D L I}=\mathbf{3 h}$ & $\mathbf{D L I}=\mathbf{7 2} \mathbf{h}$ \\
\hline $\mathrm{T}: \mathrm{M}$ & 1.68 & 0.74 & 0.75 \\
\hline $\mathrm{T}: \mathrm{S}$ & 0.69 & 0.60 & 0.18 \\
\hline
\end{tabular}

Table 1. Tumor-to-Muscle (T/M) and Tumor-to-Skin (T/S) ratios of redaporfin at various DLIs obtained from C57BL/6J mice bearing LLC tumors.

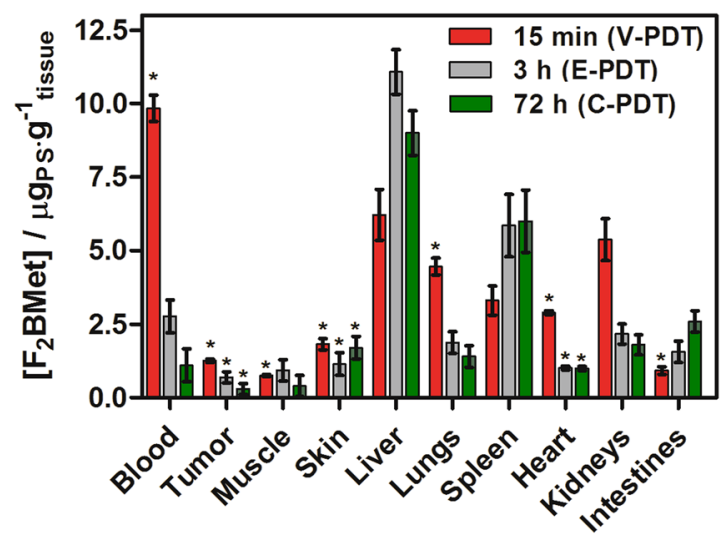

Figure 3. Biodistribution of redaporfin in blood, tumor and other tissues at: $15 \mathrm{~min}$ (red), $3 \mathrm{~h}$ post-injection (gray) and $72 \mathrm{~h}$ post-injection (green). Average values are shown with error bars representing the SEM. Results were considered as statistically significant with a confidence level of $95 \%(\mathrm{p}<0.05)$.

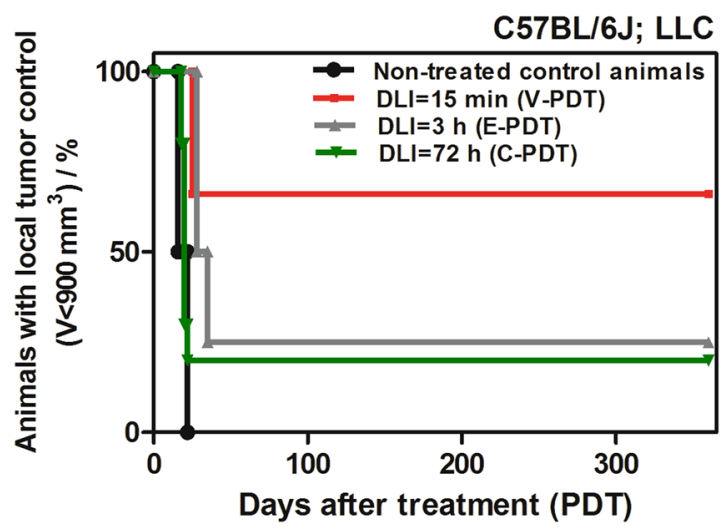

Figure 4. Kaplan-Meier analysis of the untreated mice and mice treated with redaporfin-PDT with time interval: $15 \mathrm{~min}(\mathrm{~N}=6), 3 \mathrm{~h}$ and $72 \mathrm{~h}(\mathrm{~N}=7)$.

inflammatory response following E-PDT and mild inflammatory reaction after C-PDT. Therapeutic success was estimated using Kaplan-Meier analysis, which presents the survival data of mice within a specified amount of time after PDT (Fig. 4).

In all PDT-treated mice, tumor growth was delayed compared to the control group and, consequently, partial or total tumor remission occurred. Tumor regrowth was observed up to 2 months after therapy especially after C-PDT, in half of the mice after E-PDT and in approximately $33 \%$ of the mice after V-PDT. Importantly, after this period of time a completed permanent tumor remission was achieved. Furthermore, therapeutic efficacy after V-PDT was much better (approximately 65\% cure rate) than following E-PDT or C-PDT, for which only about $25 \%$ long-term cure rate was observed. Although cellular-targeted treatment like C-PDT or E-PDT failed to induce as effective tumor regression as V-PDT, it did retard tumor growth. This effect may be related to its relatively low PS concentration at $3 \mathrm{~h}$ or $72 \mathrm{~h}$ post-injection, as well as a less favorable biodistribution that may be insufficient to achieve PDT efficacy. V-PDT is therefore more effective therapeutic approach using redaporfin as photosensitizer than E-PDT or C-PDT. In E-PDT regimen light is delivered within $15 \mathrm{~min}$ after the photosensitizer intravenous administration, while it is still present within the vascular compartment. These results are also in an agreement with biodistribution studies indicating that tumor-to-muscle or to skin tissue ratios reach the highest values after $15 \mathrm{~min}$ than $3 \mathrm{~h}$ or $72 \mathrm{~h}$ post-i.v. injection of the photosensitizer. Nevertheless, the results of in vivo experiments indicate that the use of PDT against LLC tumors increases the average lifetime of animals in all three 
(a)

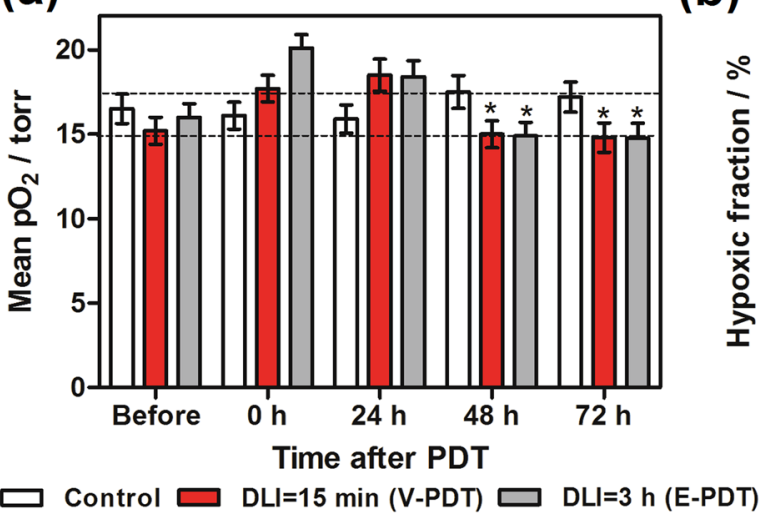

(b)

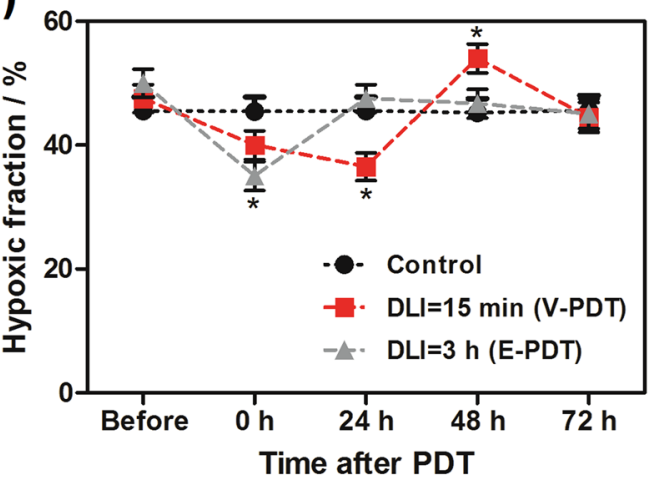

Figure 5. Changes in the oxygenation of tumors, determined from oxygen maps in control animals (a) N: 4-7 in each time interval and PDT-treated groups: with DLI $=15 \mathrm{~min}, \mathrm{~N}: 4-9$ and DLI $=3 \mathrm{~h}, \mathrm{~N}: 4-10$. (b) Hypoxic area was calculated as percentage of pixels with $\mathrm{pO}_{2}$ value less or equal to 10 torr in each tumor $\mathrm{pO}_{2}$ map. Results were considered as statistically significant with a confidence level of $95 \%(\mathrm{p}<0.05)$.

experimental groups. In the case of control tumors, this time is only 15 days. Subjecting tumor to $\mathrm{F}_{2} \mathrm{BMet}-\mathrm{PDT}$ leads to about $20 \%$ of long-term cures in the case of a protocol with DLI $=72 \mathrm{~h}, 25 \%$ for DLI $=3 \mathrm{~h}$ and $67 \%$ in the case of DLI $=15 \mathrm{~min}$. Significant differences can be seen in the initial observation period - LLC tumors treated with E-PDT are characterized initially by a good response to the therapeutic protocol used (swelling and edema), and tumor recurrences are observed approximately 30 days after the PDT. Such low PDT efficacy in C-PDT or E-PDT is surprising, due to delivered light doses, which in the applied schemes were significantly higher $\left(>100 \mathrm{~J} / \mathrm{cm}^{2}\right)$ in comparison to the doses normally used for $\mathrm{F}_{2}$ BMet-PDT $\left(74 \mathrm{~J} / \mathrm{cm}^{2}\right)^{46-48}$.

Differences in the effectiveness of therapy result primarily from the selected tumor model, which is characterized by a very high degree of invasiveness, fast growth and relatively low vascularity. It is a model classified as one of the most resistant to treatment, which is also confirmed by the results obtained in the present work - despite protocols targeting cancer cells, which theoretically should prove effective, the percentage of cured animals was only $20 \%$. This effect may result from poor tumor tissue perfusion, resulting in weak PS penetration of the tumor.

Vascular Perfusion and hypoxic areas in LLC tumors after PDT. PDT causes rapid vascular damage, providing that a short drug to light period is applied. This effect was expected to produce a dramatic decrease in tumor tissue oxygenation. Surprisingly, oximetric maps of tumors (Fig. 5) revealed an increase in $\mathrm{pO}_{2}$ values and a decrease in HF10 immediately after treatment. Mean $\mathrm{pO}_{2}$ increased from approximately 15 torr to approximately 20 torr immediately after treatment, then at $48 \mathrm{~h}$ returned to the initial level.

Similarly, the hypoxic fraction determined from EPR imaging in untreated tumors was approximately $50 \%$, after PDT it decreased to 35\%, and then returned to initial levels. Furthermore, to assess PDT-induced hypoxic area in LLC tumors, the Hypoxyprobe (pimonidazole hydrochloride) was used and immunohistochemical analysis was performed. Pimonidazole is a 2-nitroimidazole that is reductively activated specifically in hypoxic cells and forms stable adducts with thiol groups in proteins, peptides, and amino acids ${ }^{29}$. It is worthy to noticing that amount of pimonidazole that is detected in tissue is directly proportional to the level of hypoxia within tumors. Figure 6 shows relatively low hypoxic area in LLC untreated tumors. However, after PDT treatment the hypoxia were more prominent especially for V-PDT. The increase in hypoxic area after V-PDT attains a higher value than after E-PDT or C-PDT. At $2 \mathrm{~h}$ post PDT, the hypoxic fraction increased significantly and reached the highest values for V-PDT, followed by E-PDT (moderate) and C-PDT that is notable as intense green spots (see Fig. 7). Moreover, after PDT tumor hypoxia was more heterogeneous in comparison with relatively more homogeneous enhancement distribution pattern observed for untreated control tumors.

Based on the image analysis we have also estimated the fraction of positively staining section (percentage of green pixels determined from the ratio of the sum of green pixels to the total tumor area in each image), Fig. 7. The mice treated with V-PDT and E-PDT showed a significant increase in pimonidazole accumulation $(26.2 \%$ and $16.1 \%$, respectively) $2 \mathrm{~h}$ after PDT. These results indicate the increase in the PDT-induced hypoxia immediately after the treatment.

Furthermore, to better understanding the short-term and acute effects observed after photodynamic treatment, in the next stage of studies, we examined the tumor oxygenation and vascular effect after V-PDT and E-PDT. The detailed examination were performed especially for V-PDT - the phototherapeutic protocol characterized by the highest therapeutic efficacy (see Fig. 4.) The results were corroborated by more in-depth analysis of two-dimensional oxygen maps. The maps were acquired from the tumor area using a surface coil. Depth sensitivity was up to $6 \mathrm{~mm}$ and each pixel in the map represents $\mathrm{pO}_{2}$ averaged over this depth. As tumor size was approximately 3-4 mm, the maps encompassed the whole tumor volume. The mean $\mathrm{pO}_{2}$ values (Fig. 8) are averaged across the whole map, whereas the histograms (Fig. 8) represent the distribution of $\mathrm{pO}_{2}$ values from individual pixels. 


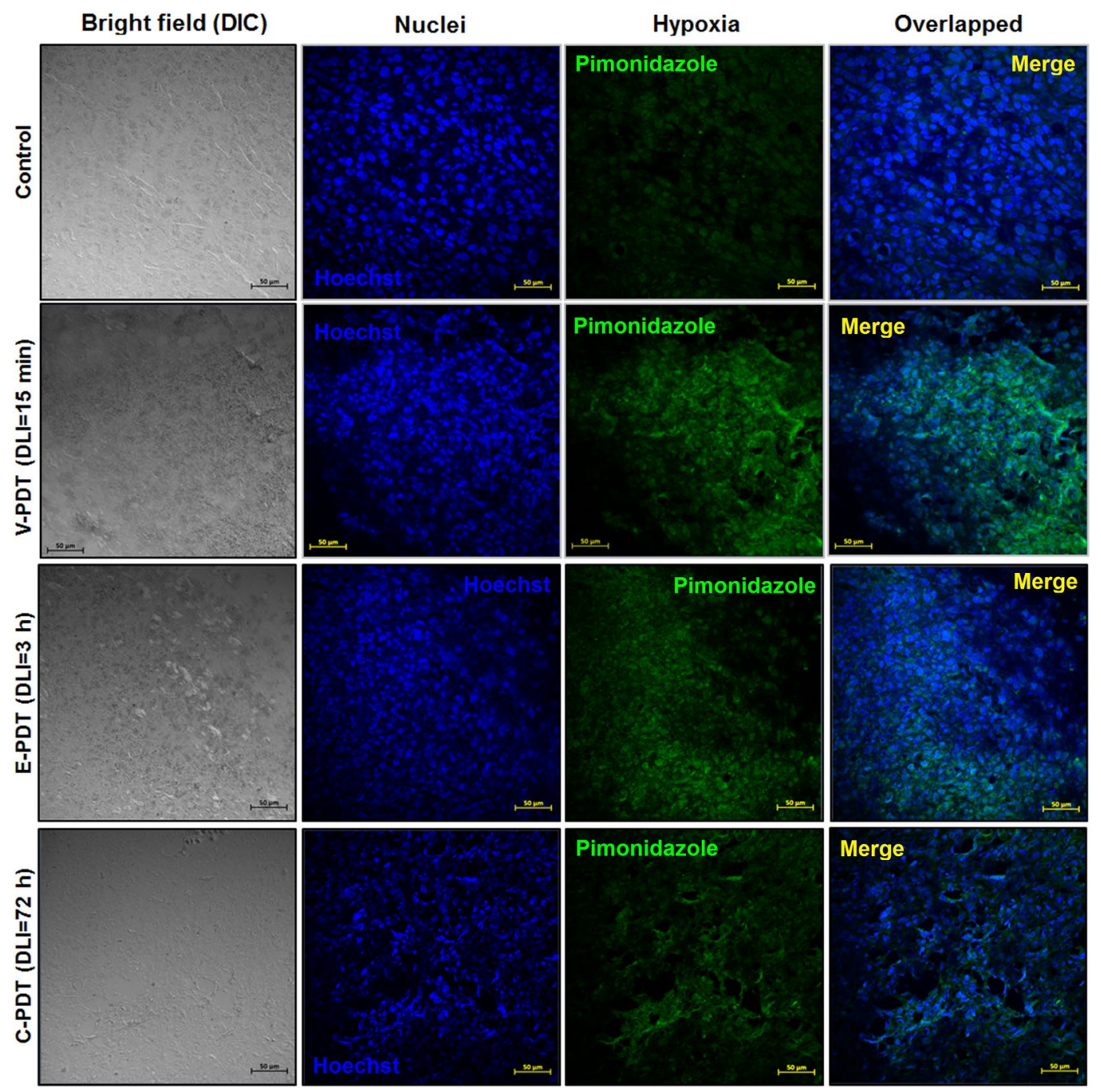

Figure 6. Pimonidazole staining of LLC tumor tissue, before (control) and $2 \mathrm{~h}$ after PDT. Hypoxic region stained by pimonidazole is shown in green fluorescence signal.

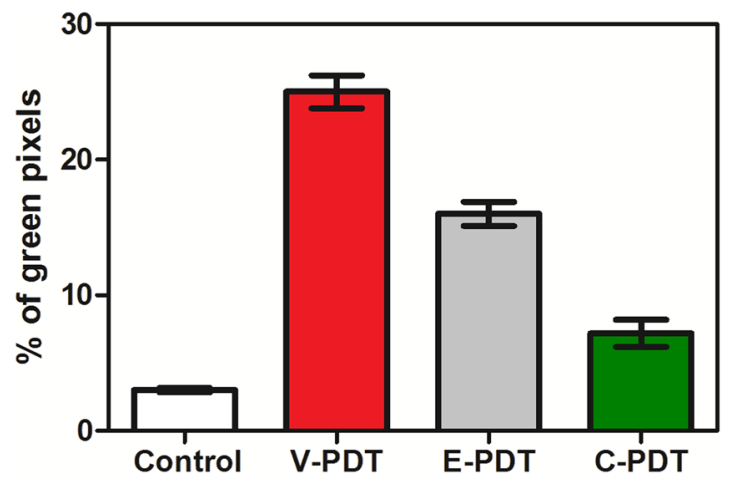

Figure 7. Changes in hypoxic area (pimonidazole positive) $2 \mathrm{~h}$ after PDT determined from IHC imaging. Values present the ratio of the sum of green pixels to the total tumor area in each image, with SEM.

The histograms show a significant shift towards increased $\mathrm{pO}_{2}$ values in of treated tumor at $24 \mathrm{~h}$, which again shift back towards lower values at 48 and $72 \mathrm{~h}$. On the other hand, strong vasculature destruction after PDT was observed by both Doppler ultrasound (Fig. 9) and immunohistochemistry. Doppler USG examination of irradiated tumors showed a total occlusion of blood flow in large vessels immediately after illumination in both types of PDT studied (Fig. 9). 
(a)

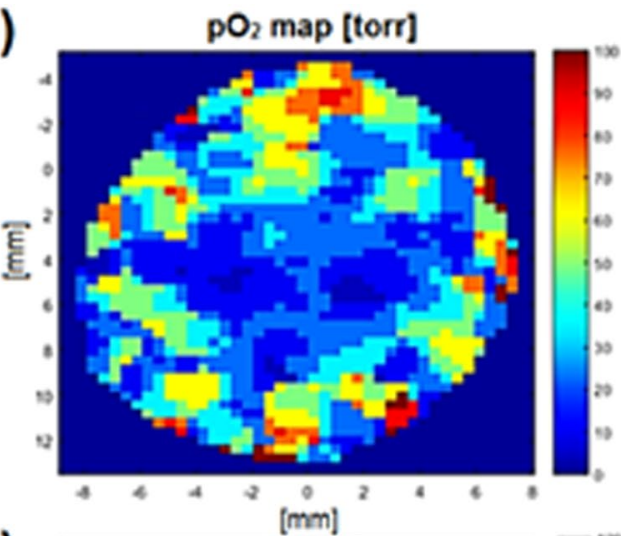

(b)

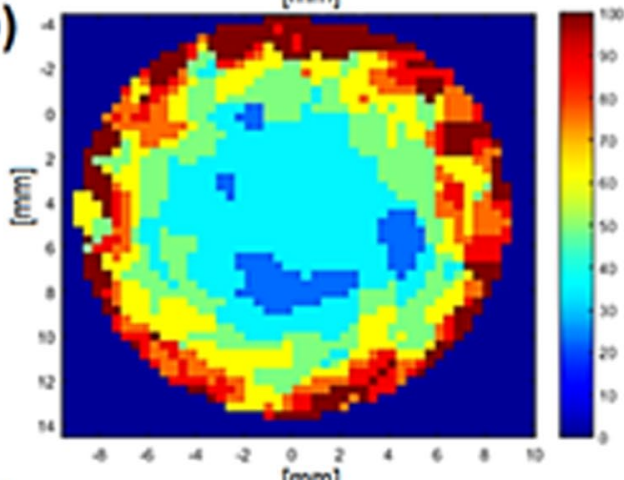

(c)

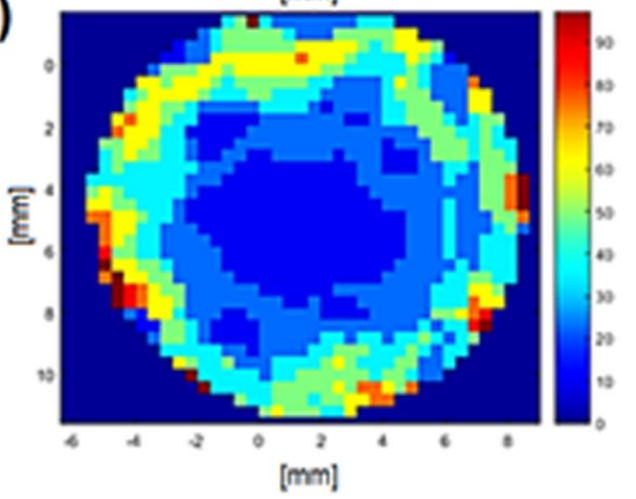

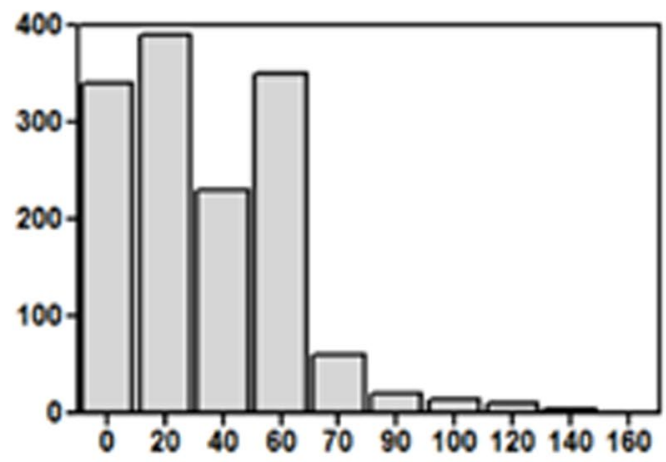
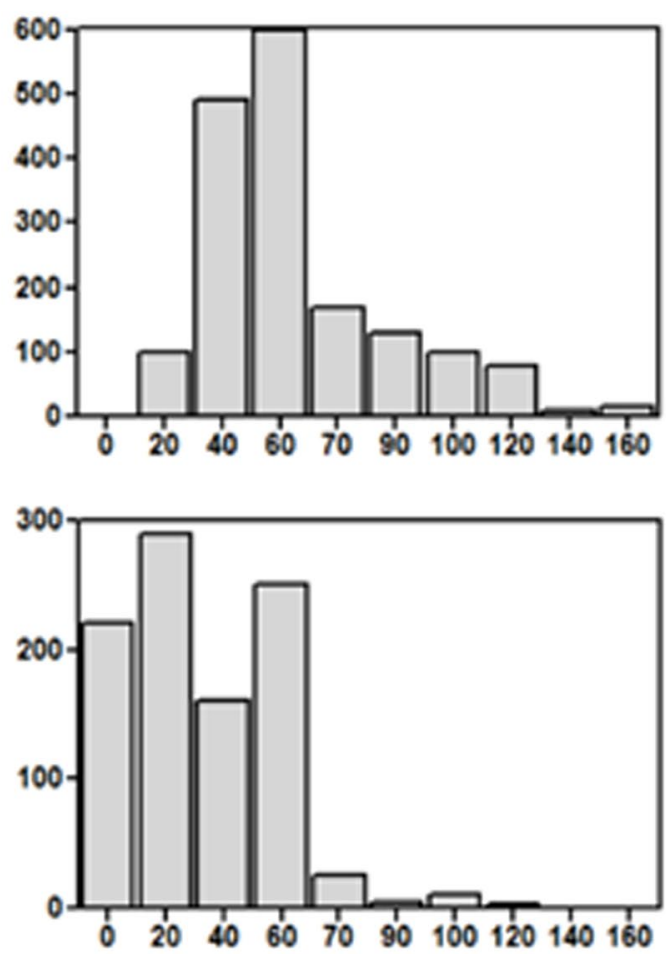

Figure 8. Representative oxygen maps of the area of interest (tumor is in the central part) with corresponding histogram presentation of $\mathrm{pO}_{2}$ level: A - before, $\mathrm{B}-24 \mathrm{~h}$ and $\mathrm{C}-72 \mathrm{~h}$ after illumination. Color bars show the $\mathrm{pO}_{2}$ scale from 0 (dark blue) to $100 \mathrm{~mm} \mathrm{Hg}$ (red). Histograms show the distribution of the $\mathrm{pO}_{2}$ values from the individual pixels, with a distinct shift towards higher oxygenation at $24 \mathrm{~h}$ after V-PDT.

The amount of large functional vessels decreased from $2-3 \%$ to $0 \%$, indicating a total shut-down of these vessels. Evidence indicating the lack of blood flow remained at 24, 48 and $72 \mathrm{~h}$ after illumination (Fig. 10). In contrast to Doppler ultrasound, immunohistological detection of endothelial cells shows all vasculature - both functioning and non-functioning, small and large vessels. As shown in Fig. 10b, a gradual decrease in the number of endothelial cells was observed, from $9 \%$ in untreated tumors to $5 \%$ at $72 \mathrm{~h}$ after both DLI $=15 \mathrm{~min}$ and DLI $=3 \mathrm{~h}$, indicating destruction of the tumor vascular system.

Large areas of tissue degeneration with many dilated or ruptured vessels were observed in tumor slices at the $48 \mathrm{~h}$ time point. At $72 \mathrm{~h}$ after treatment, evidence of vascular damage and tissue disintegration was clear, while the level of the vasculature in the control group remained constant at these time points.

Molecular analysis of VEGF levels (Fig. 11) showed that the vascular damage response molecule is present in treated tissue at a slightly higher level in comparison to control values and shows a dramatic increase at $72 \mathrm{~h}$ after $\mathrm{DLI}=3 \mathrm{~h}$. In the control group VEGF remained at a constant low level. Most notably, PDT performed at $15 \mathrm{~min}$ post PS injection led to progressive decrease in VEGF level which also contributed the final therapeutic outcome. Beginning a few hours after PDT, extensive edema accompanied by areas of noticeable congested tissue were observed, as can be seen both in the photographs and in ultrasound images (Fig. 11). 

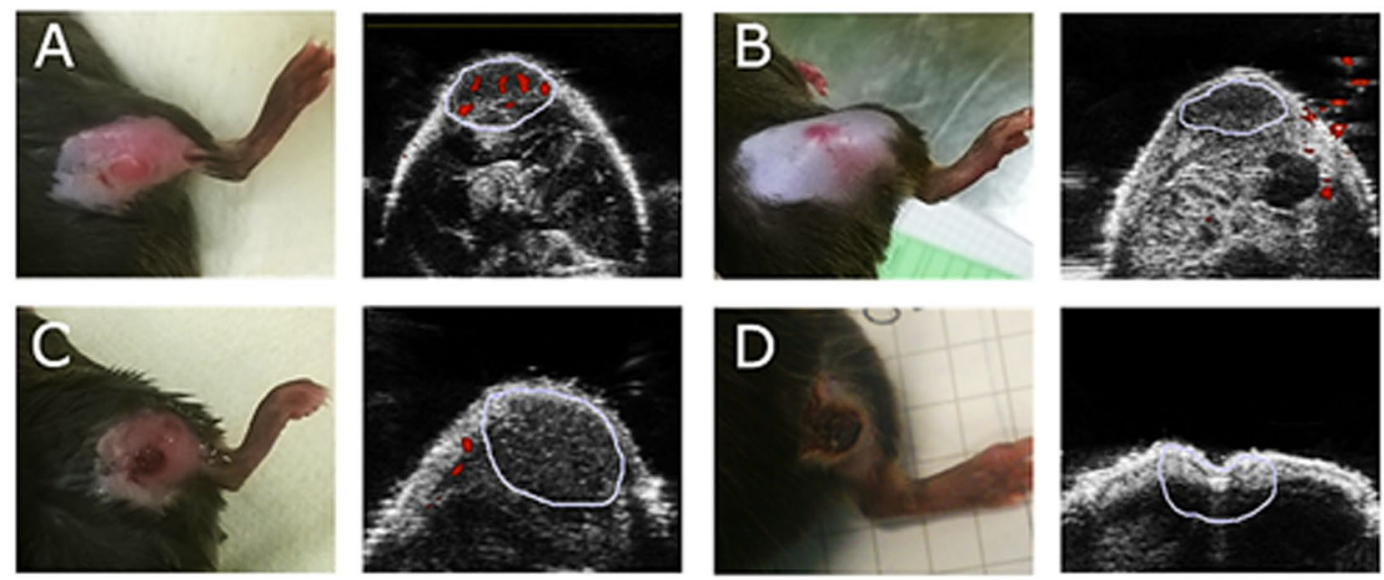

Figure 9. Representative photographs (left) and Power Doppler images (right) of tumors growing in the mouse leg. A-before, B- immediately after, C-24 h after and D-48 h after treatment (V-PDT). The area marked in blue corresponds to tumor or region of interest at each time point. Red shows the blood flow.

(a)

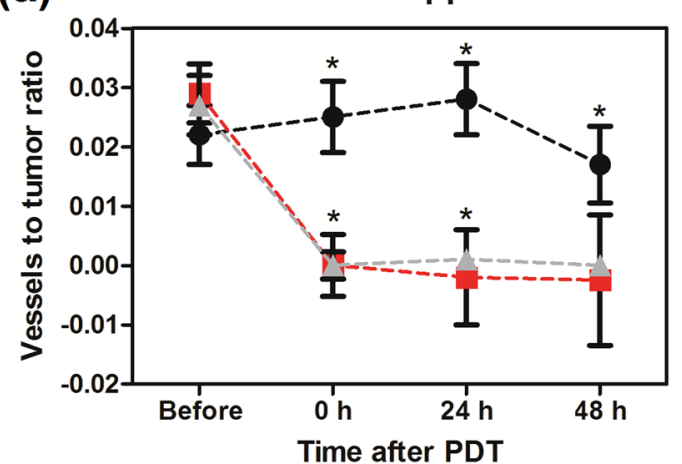

(b)

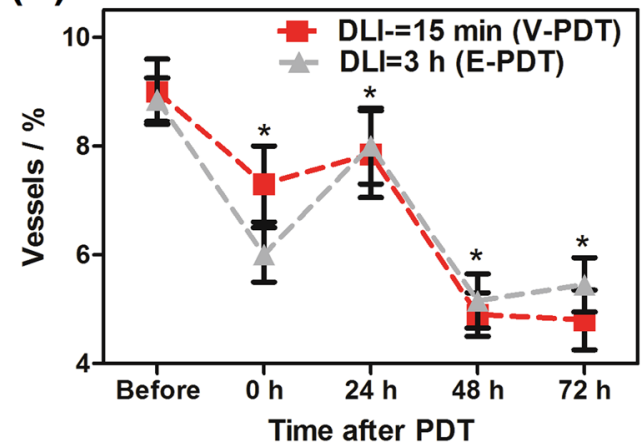

\section{Control + DLI-=15 min (V-PDT) - DLI=3 h (E-PDT)}

Figure 10. (a) Changes in tumor vasculature after PDT as determined from Power Doppler imaging. Values present the ratio of the sum of red pixels (blood flow) to the total tumor area in each image, with SEM. (b) Vascular changes in the tumors after PDT as determined from IHC. Average of vessels percentage with SEM is shown for each group. N: 4-12 in each group and given time interval. Results were considered as statistically significant with a confidence level of $95 \%(\mathrm{p}<0.05)$.

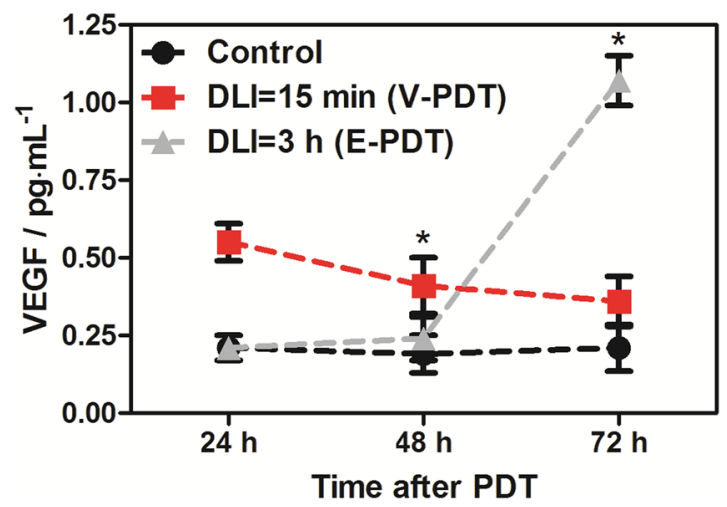

Figure 11. Changes in the VEGF level in tumor lysates $24 \mathrm{~h}, 48 \mathrm{~h}$ and $72 \mathrm{~h}$ after illumination as compared to control (K0). Values are averaged from $\mathrm{N}=3-6$ tumors with SEM. Results were considered as statistically significant with a confidence level of $95 \%(\mathrm{p}<0.05)$. 


\section{Discussion}

It is generally recognized that the most popular photosensitizers in clinical practice such as Photofrin and Foscan operate according to Type II mechanism, and in recent years the design of new drugs was focused primarily on improving the production of singlet oxygen. A totally different approach was followed in the development of Tookad Soluble which acts exclusively via Type I mechanism ${ }^{59}$. In this work we applied a series of fluorescent probes to confirm that various types of ROS are generated in vitro. The generation of superoxide ions and subsequently hydroxyl radicals contributes to the cytotoxicity of singlet oxygen and their combination gives stronger photodynamic effect leading to the cell death. The cellular uptake is also determinant of PDT efficacy and here again the significant uptake of redaporfin resulted in a greater photodynamic efficacy. Furthermore, redaporfin meets the criteria of the ideal photosensitizer, namely low dark toxicity, selectivity towards tumor tissue shortly after administration, simple formulation and rapid clearance from the body.

Our previous study demonstrated that the $\mathrm{pO}_{2}$ tissue level after PDT is an important determinant of tumor response to therapy ${ }^{31}$. Presently, using single-point $\mathrm{pO}_{2}$ measurements we have shown that severe and prolonged tumor hypoxia after vascular-targeted PDT leads to a higher percent cure rate. In the present study, our goal was to determine tumor oxygenation after redaporfin-PDT using two approaches, vascular-targeting (DLI $=15 \mathrm{~min})$ and endothelial-targeting $\left(\mathrm{DLI}=3 \mathrm{~h}\right.$ ). EPR oximetry is a non-invasive method of measuring tissue $\mathrm{pO}_{2}$ based on physical interactions between molecular oxygen and molecules of the oximetric spin probe introduced into tissue. The $\mathrm{pO}_{2}$ may be determined either spectroscopically or using an imager to map oxygen in studied volume. We have applied a soluble nitroxide given either i.v. or intratumorally to acquire a two-dimensional oxygen map of the tumor. Each $2 \times 2 \mathrm{~mm}$ pixel of the image presents a $\mathrm{pO}_{2}$ value, and in the third dimension (depth) the $\mathrm{pO}_{2}$ is averaged. We have analyzed both the mean and median value of $\mathrm{pO}_{2}$ from all pixels in the image from each tumor and there is a statistically significant difference showing an increase in $\mathrm{pO}_{2}$ immediately after both treatments and at $24 \mathrm{~h}$. However, showing a single $\mathrm{pO}_{2}$ value is not an appropriate parameter to characterize a map that contains spatial distribution. A more fitting parameter that reflects changes in $\mathrm{pO}_{2}$ maps for particular treatment group and time seems to be the hypoxic fraction (HF10), showing a percentage of pixels below 10 torr. However, the best descriptor is the histogram of all of the tumor $\mathrm{pO}_{2}$ values that shows a decisive shift in all $\mathrm{pO}_{2}$ values in the image. An unexpected increase in $\mathrm{pO}_{2}$ post treatment, inconsistent with vasculature shut-down, was observed due to the inadvertent choice of the region of interest in our imaging. Two-dimensional imaging is a preferred choice for small volume tumors, but in the case of extensive edema, it prevents imaging of the tumor only and instead averages over the whole area depth. Additionally, edema can cause changes in temperature, viscosity, $\mathrm{pH}$, or $\mathrm{pO}_{2}$ of the tumor microenvironment potentially resulting in an incorrect interpretation of results at the $24 \mathrm{~h}$ time point, especially when previously similar experiments using different spin probes show opposite effects. EPR spectroscopy measurement data from 3CP imaging and LiPc probes could vary because of lower sensitivity to oxygen, localized implementation of LiPc crystal versus distribution spin probe in the whole tumor, or averaging $\mathrm{pO}_{2}$ value by projecting spectral dimension along tumor. Applying three-dimensional spatial-spectral imaging would be more appropriate in future experiments and would allow for selection of a region of interest and measuring $\mathrm{pO}_{2}$ only from tumor tissue.

These results are in agreement with the data published recently for $S 91$ tumors $^{31}$. What is more, at $2 \mathrm{~h}$ post PDT, the hypoxic fraction increased significantly and reached the highest values for V-PDT, followed by E-PDT (moderate) and C-PDT. These results reflect the hypoxia within the tumor, not including the edema, and agree with vascular function and density (Figs 9 and 10). Additionally, presented results verified the hypothesis that V-PDT with redaporfin induces strong local hypoxia that may be related with better therapeutic efficacy and tumor growth inhibition. Nevertheless, for cellular-targeted phototherapeutic protocols (E-PDT, C-PDT) the hypoxic area seems to be lower what can lead to intense $\mathrm{pO}_{2}$ compensatory effects and modest tumor inhibition ${ }^{31}$. Tong et al. also investigated the hypoxia phenomenon after photodynamic treatment (HPPH-PDT) with comparison to static and dynamic PET using hypoxic specific tracer 18F-FMISO combined with pharmacokinetics modeling in U87MG and MDA-MB-435 tumors. These data clearly indicated difference in tumor hypoxia in response to PDT and suggest that monitoring intrinsic and PDT-induced hypoxia can be considered as prognostic factor for further therapeutic efficacy evaluation ${ }^{29}$.

Doppler ultrasound blood flow analysis showed no differences between the two applied V-PDT and E-PDT protocols. In both groups of tumors, we observed a total arrest of blood flow in large vessels immediately after treatment. Together with accompanying edema and erythema of the illuminated area, this indicates an immediate effect of therapy with strong local response ${ }^{60}$. A total lack of blood flow was seen for next $48 \mathrm{~h}$. Therefore, similar to other common photosensitizers, such as Photofrin, application of vascular-targeted and endothelial-targeted PDT with redaporfin brings about instant and prolonged inhibition of tumor perfusion ${ }^{61}$. Immunohistological staining on endothelial cells confirmed destruction of tumor vasculature after therapy. This decrease was gradual and more pronounced at 48 and $72 \mathrm{~h}$. Vascular tissue breakdown was associated with degradation and necrosis of tumor tissue. Well-known effects of PDT, especially vascular-targeted PDT, are hypoxia and oxidative stress. Both of these factors contribute to increased VEGF expression in tumor tissue ${ }^{22,62}$. We noticed a substantial increase in VEGF at $72 \mathrm{~h}$ after DLI $=3 \mathrm{~h}$ but not after DLI $=15 \mathrm{~min}$. This suggests that despite very similar effects on vasculature, the two protocols exert different effects at the molecular level. One explanation might be that at DLI $=3 \mathrm{~h}$ the PS has longer to diffuse into cells and damage is more extensive, causing a higher response in VEGF stimulation. Another possibility is that DLI $=15 \mathrm{~min}$ caused such extensive tumor cell death, the cells were unable to respond by protein production. It is important to note that higher VEGF levels can lead to stimulation of angiogenesis and tumor regrowth.

PDT protocols examined led to tumor vasculature shut-down and endothelial cells destruction, likely leading to tumor hypoxia as evidenced by VEGF production, especially after DLI $=3 \mathrm{~h}$. The observed paradoxical increase in $\mathrm{pO}_{2}$ levels after PDT resulted from an imaging approach which included well-oxygenated areas of tumor edema that developed immediately after treatment. A significant difference in survival was observed 
between animals treated with a DLI $=3 \mathrm{~h}, \mathrm{DLI}=72 \mathrm{~h}$ protocol (about $25 \%$ of animals without tumor regrowth) and a $15 \mathrm{~min}$ DLI protocol (67\% cure rate). This result indicates a significant advantage of V-PDT. Its outcome also corresponds to a high amount of PS in blood and within tumor blood vessels shortly after administration (15 min). Our studies also confirmed that a key factor for efficient PDT is a complete closure of tumor vessels. In order to achieve this outcome, short DLI protocols should be applied. Moreover, due to tumor hypoxia, PS acting via Type I photochemical mechanisms, which are less independent on $\mathrm{O}_{2}$ level, should be used in V-PDT.

\section{Methods}

Photosensitizer. Redaporfin (synthetic bacteriochlorin derivative, also known as $\mathrm{F}_{2} \mathrm{BMet}$ or LUZ11) was kindly provided by Luzitin S.A, Coimbra, Portugal, as a powder samples transported under appropriate atmosphere conditions. Redaporfin-CrEL formulation was prepared by dilution of a concentrated solution of CrEL:EtOH (1:5) in PBS to obtain CrEL:EtOH:PBS (0.2:1:98.8 v/v/v) $)^{4,46,63}$. As an administration vehicle the Cremophor EL micelles in saline solutions was used. The final dilution of Cremophor EL/ethanol mixture at applied non-toxic dose was subsequently injected into mice intravenously via tail vein at dose of $1.5 \mathrm{mg} / \mathrm{kg} \mathrm{B.W}$. The injected volume varied between $0.2 \mathrm{ml}$ and $0.5 \mathrm{ml}$ depending on individual's animal weight, either 15 minutes or 3 hours prior to illumination. The absorption spectra of redaporfin were measured using HP8453 spectrophotometer in $1 \mathrm{~cm}$ path-length quartz cell. Fluorescence measurements were performed using Perkin Elmer Fluorescence Spectrometer LS 55 with $\lambda_{\mathrm{ex}}=505 \mathrm{~nm}$ and $\lambda_{\mathrm{em}}=700-800$, respectively.

In vitro evaluation. In vitro evaluation was performed using the experimental conditions and overall procedures described in our previous work ${ }^{48}$.

Cell culture. Lewis lung carcinoma (LLC) cells were grown in RPMI-1640 with addition of 10\% FBS and supplemented by antibiotics ( $100 \mathrm{IU} / \mathrm{mL}$ penicillin and $100 \mathrm{mg} / \mathrm{mL}$ streptomycin). The cells were cultured in incubator maintained at $37^{\circ} \mathrm{C}$ with $5 \% \mathrm{CO}_{2}$ under fully humidified conditions. All experiments were performed on cells in the logarithmic phase of growth. Media were replaced every 2 days and cells were subcultured using $0.25 \%$ trypsin-EDTA ${ }^{48}$.

Cellular uptake. To estimate the possibility of efficient accumulation of photosensitizer in LLC cells the time-dependent cellular uptake experiment were performed. LLC cells were seeded on 96-plate microplate $\left(10^{4}\right.$ per well). After $24 \mathrm{~h}$, the cells were incubated with redaporfin $(5 \mu \mathrm{M})$ for time intervals from $2 \mathrm{~h}$ up to $24 \mathrm{~h}$. Redaporfin solutions were prepared by diluting its stock solution in DMSO with the culture medium to the desired final concentration $(5 \mu \mathrm{M})$. The content of DMSO did not exceed $0.5 \%$. After each incubation time, the cells were washed twice with PBS and solubilized in $30 \mu \mathrm{L}$ of Triton X-100 and $70 \mu \mathrm{L}$ of DMSO/ethanol solution (1:3). The accumulation of redaporfin was detected by fluorescence measurements $\left(\lambda_{\text {exc }}=505, \lambda_{\text {em }}=750 \mathrm{~nm}\right)$ with the microplate reader (Tecan Infinite M200 Reader) ${ }^{48}$.

Dark cytotoxicity and cells viability assay. To assess the dark cytotoxicity of redaporfin, LLC cells seeded on 96-plate microplate $\left(10^{4}\right.$ per well) were incubated with redaporfin solution prepared in growth medium in concentrations from 0 to $100 \mu \mathrm{M}$. Treated cultures were incubated for ca. $24 \mathrm{~h}$ in the dark. Next, the redaporfin solution of each well was removed, cells were washed in PBS and fresh culture medium supplemented with FBS and antibiotics was added to each well and cells were returned to the incubator for $24 \mathrm{~h}$. Next, the cells viability was calculated based on the MTT and AlamarBlue assay. The MTT (3-(4,5-dimethylthiazol-2-yl)2,5-diphenyl tetrazolium bromide) and AlamarBlue assays were used to quantify cell survival after photodynamic effect. MTT or AlamarBlue dissolved in PBS at content $10 \%$ of final solution were added to each well and the microplates were further incubated for ca. $3 \mathrm{~h}$. In the case of MTT, medium was then discarded and $100 \mu \mathrm{L}$ of mixture of DMSO/ methanol (1:1) were added to the cultures and mixed thoroughly to dissolve the dark blue crystals of formazan. Formazan quantification was performed using an automatic microplate reader (Tecan Infinite M200 Reader) by absorbance measurements with a $565 \mathrm{~nm}$ test wavelength. Resorufin quantification was performed using by fluorescence measurements with a $605 \mathrm{~nm}$ test wavelength ${ }^{48}$.

Photodynamic effect. The nontoxic concentration of redaporfin $(15 \mu \mathrm{M})$ was used for cells incubation. Cells were incubated for $3 \mathrm{~h}$ in the dark with redaporfin solution or with in a culture medium (RPMI1640 supplemented with $10 \%$ FBS and antibiotics). After this incubation time, the cells were washed two times with PBS with $\mathrm{Ca}^{2+}$ and $\mathrm{Mg}^{2+}$ and irradiated with a $735 \pm 20 \mathrm{~nm}$ LED light for various time intervals. Next, the cells were washed with fresh medium and the plates were returned to the incubator for $24 \mathrm{~h}$. Cell viability was determined by MTT and AlamarBlue assays in independent experiments performed $24 \mathrm{~h}$ post-irradiation. Images from the cell morphology before and $24 \mathrm{~h}$ post-PDT were obtained using optical microscope (Olympus) ${ }^{48}$.

Flow cytometry analysis. Cell death after photodynamic effect was quantified for selected condition using the AnnexinV-FITC/PI double staining kit (Sigma Aldrich). The cell death of LLC cells was investigated $4 \mathrm{~h}$ after photodynamic treatment. Briefly, the LLC cells $\left(1 \cdot 10^{5}\right.$ per well) were cultured overnight in 12 -well plates. Then cells were subjected to redaporfin-mediated photodynamic effect (described above), collected by centrifugation and washed twice in Hank's Balanced Salt Solution (HBBS). The cells were then resuspended in $500 \mu \mathrm{L}$ binding buffer and stained with annexin V-FITC and PI according to the manufacturer's instructions (Sigma Aldrich). Stained LLC cells were then examined using Guava ${ }^{\circledR}$ easyCyte $^{\mathrm{TM}}$ flow cytometer. Obtained data were analyzed using FlowJo 10.5.3 software (BD Bioscience). 
Detection of reactive oxygen species. The $3^{\prime}$-p-(aminophenyl)fluorescein (APF), $3^{\prime}$-p-(hydroxyphenyl)fluorescein (HPF), Singlet Oxygen Sensor Green (SOSG) and dihydroethidium (DHE) fluorescent probes were employed for detection of reactive oxygen species formation during illumination. LLC cells were incubated with $15 \mu \mathrm{M}$ redaporfin solution prepared in OptiMem for $3 \mathrm{~h}$. Two hours prior to the end of incubation each probe at concentration at $20 \mu \mathrm{M}$ was added to the solution In case of SOSG, cells were incubated with standard maintenance medium (SMM)-based solutions ${ }^{64,65}$. Then, cells were washed with PBS with $\mathrm{Ca}^{2+}$ and $\mathrm{Mg}^{2+}$ and irradiated with the $735 \pm 20 \mathrm{~nm}$ light source for various time intervals. The probes fluorescence signals (for APF and HPF: $\lambda_{\text {exc }}=488 \mathrm{~nm}, \lambda_{\text {em }}=515 \mathrm{~nm}$, for SOSG: $\lambda_{\text {exc }}=505 \mathrm{~nm}, \lambda_{\text {em }}=525 \mathrm{~nm}$ and $\lambda_{\text {exc }}=480 \mathrm{~nm}, \lambda_{\text {em }}=580 \mathrm{~nm}$ for DHE, respectively) were determined using a microplate reader (Tecan Infinite M200 Reader) immediately before and after illumination ${ }^{48}$.

Animal and tumor model. Male C57BL/6J mice, initially 8-12 weeks old and weighing approximately $20 \mathrm{~g}$ were originally obtained from the animal breeding facility at Faculty of Biochemistry, Biophysics and Biotechnology of the Jagiellonian University (Cracow, Poland). All experimental procedures were approved by First Ethic Local Committee of Jagiellonian University (permission no 2/2015 and 190/2018) and experiments were performed in accordance with the relevant guidelines and regulations. Mice were housed in standard laboratory conditions with LD:12/12, humidity: $60 \%$, temperature: $23^{\circ} \mathrm{C}$ with unlimited access to standard chow diet and drinking water. The Lewis lung carcinoma (LLC) cells were growing as a monolayer at $37^{\circ} \mathrm{C}$ in a humidified atmosphere of 5\% $\mathrm{CO}_{2} / 95 \%$ air in RPMI- 1640 supplemented with $10 \%$ heat-inactivated fetal bovine serum (BioTech, Poland) and penicillin-streptomycin under sterile tissue culture conditions. The final suspension of tumor cells ready for intradermal injection was estimated at 0.5 million per $1 \mu$ l of PBS solution and in that form introduced into the skin of the right hind leg. Tumor selection to experiments was performed when tumor implants reached the size of 30-50 $\mathrm{mm}^{3}$ after 7-9 days, and then the animals were randomly assigned to one of the following groups due to the protocol applied afterwards: DLI $=15 \mathrm{~min}, \mathrm{DLI}=3 \mathrm{~h}, \mathrm{DLI}=72 \mathrm{~h}$ and $\mathrm{K} 0$ - control group. The therapeutic procedures were started when tumors reach more than $0.5 \mathrm{~cm}$ in each diameter (which corresponds to tumor volume about $80-100 \mathrm{~mm}^{3}$ ). LLC is a well described mouse solid tumor, growing in an encysted form, therefore it is known to cause no significant discomfort to the tumor bearing animals. The growth of the tumor was monitored by caliper every 24 hours and the volume was calculated.

Biodistribution. LLC cells were implanted subcutaneously into the right thigh of male C57BL/6J mice (as described above). The i.v. injection of photosensitizer was done in each animal at a dose of $1.5 \mathrm{mg} \cdot \mathrm{kg}^{-1}$ into the tail vein of each animal and tissue distribution was evaluated at $15 \mathrm{~min}, 3 \mathrm{~h}$ and $72 \mathrm{~h}$ post-administration. In general, experiments were performed according to procedure described in our previous work ${ }^{48}$. At appropriate time post-injection, the mice were anesthetized with ketamine and xylazine and sacrificed. For each animal, selected organs and tissue samples were collected separately and weighed. The content of redaporfin in the tissue samples was determined by fluorescence measurements. To extract the PS, tissue samples were homogenized in EtOH/ DMSO solution (75:25) using a Yellowline by IKA DI 25 basic animal tissue homogenizer. The homogenates were centrifuged, the supernatants were collected, and the pellets was re-extracted four more times using the procedure described above to ensure complete recovery of the drug. The extracts were pooled and the fluorescence analysis of the extracts was done. The samples were excited at $505 \mathrm{~nm}$, and the fluorescence spectra were recorded in a range of $600-800 \mathrm{~nm}$. The amount of redaporfin in the tissues was reported as the average from four animals (with the standard error of the mean, SEM). The redaporfin concentration was estimated based on fluorescence intensity of redaporfin in prepared samples and comparison with the calibration curve $\mathrm{e}^{48}$.

Photodynamic therapy in vivo. Prior to therapeutic procedure the tumor leg was shaved carefully with a razor blade in the area of the tumor and surrounding tissue. The photodynamic therapy was performed according to procedure described in our previous work ${ }^{48}$. The tumor illumination was performed at DLI $=15 \mathrm{~min}, \mathrm{DLI}=3 \mathrm{~h}$ and DLI $=72 \mathrm{~h}$ using a NIR-laser light (Omicron laser model LDM750.300.CWA.L.M equipped with optical fiber model FD/Medlight (Ecublens, Switzerland) was used as a light source) at $750 \mathrm{~nm}$, light dose at $105 \mathrm{~J} \cdot \mathrm{cm}^{-2}$ and a laser power of $130 \mathrm{~mW}$. The illuminated area with a diameter of $1.3 \mathrm{~cm}$ was kept constant during irradiation. Survival curves were determined by Kaplan- Meier analysis that present the survival data for a certain amount of time after photodynamic treatment.

In vivo Power Doppler imaging. High Resolution Ultrasound Imaging System, devoted to small experimental animals (Visual Sonics Vevo 2100) with MS-550D serial transducer was used. During imaging body temperature was controlled by heating, and maintained at $37^{\circ} \mathrm{C}$. Anesthesia was induced by $3 \mathrm{vol} \%$ isoflurane (Aerrane, Baxter Polska Sp. z o. o., Poland) and then maintained at 1.5-2.0 vol\% isoflurane in the air, delivered at $1.2 \mathrm{l} / \mathrm{min}$. For the confirmation of the tumor position, a B-mode ultrasound (grey scale) was performed with a central frequency $40 \mathrm{MHz}$. Power Doppler (PD) ultrasound contain color imaging of vascularization was performed with central frequency $32 \mathrm{MHz}$ and pulse repetition frequency (PRF) $3-4 \mathrm{kHz}$. Two-dimensional tumor sections with a field of view (FOV) $12 \times 12 \mathrm{~mm}$ were collected along the third tumor dimension using motorized transducer holder, resulting in a $3 \mathrm{D}$ image. The in plane (XY) resolution was up to $15 \mu \mathrm{m}$ and $\mathrm{Z}$ resolution was equal $200 \mu \mathrm{m}$. The volume of the vasculature was calculated as a sum of pixels of functional vessels detected in each image slice. The tumor volume was a sum of pixels of tumor area marked by hand on each image slice.

EPR imaging. Approximately 10 minutes prior to measurements, animals were sedated and anesthetized with inhaled anesthesia as describe in Power Doppler Imaging section. Animal temperature was maintained at $37^{\circ} \mathrm{C}$ by using a thermal blanket. 3D EPR spatial spectral imaging was conducted using Elexys 540 L-band continuous wave system (Bruker, Germany) with a surface coil. Two spatial and one spectral dimension imaging allowed obtaining 2D images of spin probe distribution, and for each pixel whole EPR spectrum was acquired. The tumor 
size was approximately 4-6 $\mathrm{mm}$ in thickness, and at L-band the surface coil acquires information from up to $6 \mathrm{~mm}$. Therefore, the collected 2D data was a sum of oximetric spin probe signal in the volume of around $1 \mathrm{~cm}^{3}$ in the direct proximity of the coil. As a spin probe 3-carboxyl proxyl (Sigma Aldrich) was used. The spin probe was injected at volume of $200 \mu \mathrm{l}(9 \mathrm{mg} / \mathrm{ml})$ intraperitoneally before and right after PDT or directly into the tumor at volume of $10 \mu \mathrm{l}$ at 24,48 and 72 hours after therapy. EPR measurement parameters were as follows: amplitude modulation $0.7 \mathrm{G}$, modulation frequency $30 \mathrm{kHz}$, sweep time was around $1.5 \mathrm{~s}, 10.75 \mathrm{~mW}$ microwave power. For imaging low field line with center field $390.95 \mathrm{G}$ was used. Spatial - spectral imaging was performed with two spatial and one spectral dimension. Maximum gradient was set as $3 \mathrm{G} / \mathrm{cm}$. Total number of projections was 434 (31 spatial and 14 spectral). Total imaging time was around 30 minutes.

Image reconstruction and post-processing. Images were reconstructed using FBP from EPR-IT software with homebuilt modifications. 512 points per spectrum were acquired and then subsampled to 128 . The number of projections were interpolated by factor of 4 . Projections were filtered using Ram-Lak filter with cutoff equal 0.5. Spatial field of view FOV $=4.24 \mathrm{~cm}$ and spectral field of view was $5 \mathrm{G}$. Image size was set to 128 pixels in each dimension. For spectrum from each pixel peak to peak linewidth distance was calculated and converted to $\mathrm{pO}_{2}$ value. Calibration curve was performed for three $\mathrm{pO}_{2}$ values: 0,3 and $21 \%$ of oxygen in $3 \mathrm{CP}$ solution. Finally, spatial images of spin probe distribution were converted to $2 \mathrm{D}$ oxygen maps using calibration curve. Spatial resolution was less than $2 \mathrm{~mm}$ as determined earlier using phantom imaging. Hypoxic fraction 10 (HF10) was calculated as the number of pixels value less or equal to 10 torr divided by number of all pixels in our region of interest.

Immunohistochemistry with pimonidazole and confocal imaging. Immunohistochemical staining was performed to observe ex-vivo tissue hypoxia with Hydroxyprobe ${ }^{\mathrm{TM}}$ kit (Hydroxyprobe Inc., Burlington, MA). Multiple mice bearing LLC tumors $(\mathrm{N}=5)$ bearing LLC tumors were intravenously injected via tail vein with $60 \mathrm{mg} / \mathrm{kg}$ BW of pimonidazole before and $2 \mathrm{~h}$ after PDT treatment (described above) ${ }^{29}$. After $90 \mathrm{~min}$ of incubation of pimonidazole, mice were euthanized with ketamine/xylazine and tumors were harvested. Tumors were weighed, snap-frozen, and stored at $-80^{\circ} \mathrm{C}$. Harvested tumors were then taken in a cryostat (Leica) and cut into $5 \mu \mathrm{m}$-thick sections. Sections are placed on microscope slides for staining based on the manufacturer's instructions. Frozen slides were air dried $(30 \mathrm{~min})$ and fixed with ice-cold acetone for $10 \mathrm{~min}$. After acetone evaporation ( $30 \mathrm{~min}$ ) slides were washed two times with PBS and then incubated for 10 min in $0.3 \% \mathrm{H}_{2} \mathrm{O}_{2}$ in $\mathrm{MeOH} /$ PBS. Then, slides were washed two times $(5 \mathrm{~min})$ with PBS and blocked $1 \mathrm{~h}$ in blocking buffer $(1 \times \mathrm{TBS}, 0.3 \%$ Triton X-100, 5\% FBS). The blocking solution was removed and slides were incubated with add FITC-conjugated anti-pimonidazole primary antibody overnight at $4{ }^{\circ} \mathrm{C}$. After incubation, slides were washed three times $(5 \mathrm{~min})$ with TBS- $0.01 \%$ Tween 20 , stained with Hoechst 33342 for 10 min, rinsed with PBS, mounted with prolong gold mounting solution and coverslip. Prepared tissues were imaged with fluorescence confocal microscopy LSM880 (Carl Zeiss) with $40 \times$ magnification as desired and analyzed using ZEN software (Carl Zeiss). For further analysis, five complete and non-overlapping regions of interest (ROI) were randomly selected from each prepared slide. All microscopic images were adjusted with the same parameters; thus, tumor hypoxia was reflected directly by the pimonidazole staining color intensity (green signal).

Protein analysis and immunohistochemistry staining (IHC). Enzyme immunoassay - Quantikine M mouse ELISA kit was used to quantify vascular endothelial growth factor (VEGF) levels in control and treated tumor lysates (R\&D Systems, Minneapolis, MN). Tumors were homogenized in lysis buffer and sonicated. Buffer lysates obtained from whole dissected tumor tissue were analyzed for total protein level and subsequently processed following the manufacturer's protocol. The resulting amount of protein was presented as pg of VEGF per $1 \mathrm{mg}$ of total protein content. Tumors previously fixed in cryoprotectant were cut into $5 \mu \mathrm{m}$ slices for immunohistochemistry. 9F1 Rat monoclonal antibody against mouse endothelium (Radbound University Nijmegen Medical Centre) was used to visualize vessels. The level of secondary antibody presentation was assessed by counting the number of dark pixels in relation to the total pixel number of the whole image in 3-5 hot spots in each slice from each tumor 2-3 representative slices were microscope images were analyzed.

Statistics. For EPR imaging and oximetry statistical data analysis two-way ANOVA was performed. As a factors treatment time and treatment group were used. RiR-Tukey post-hoc test for difference number of elements in particular group did not show statistical differences for $\mathrm{p}=0.05$. For other experiments, the $\mathrm{t}$-test was applied for the evaluation of statistical significance ( $p$ values). Results were considered as statistically significant with a confidence level of $95 \%(\mathrm{p}<0.05)$. Statistical analysis was performed with the STATISTICA12.5 software (StatSoft Poland, Kraków).

\section{References}

1. Kim, E. S. In Lung Cancer and Personalized Medicine 189-209 (Springer, 2016).

2. Tsvetkova, E. \& Goss, G. Drug resistance and its significance for treatment decisions in non-small-cell lung cancer. Current oncology 19, S45 (2012).

3. Krammer, B. \& Verwanger, T. In Applied Photochemistry 377-396 (Springer, 2016)

4. Rocha, L. B., Gomes-da-Silva, L. C., Dąbrowski, J. M. \& Arnaut, L. G. Elimination of primary tumours and control of metastasis with rationally designed bacteriochlorin photodynamic therapy regimens. European Journal of Cancer 51, 1822-1830, https://doi. org/10.1016/j.ejca.2015.06.002 (2015).

5. Agostinis, P. et al. Photodynamic therapy of cancer: an update. CA: a cancer journal for clinicians 61, 250-281 (2011).

6. Oszajca, M. et al. Mechanistic studies on versatile metal-assisted hydrogen peroxide activation processes for biomedical and environmental incentives. Coordination Chemistry Reviews 327, 143-165 (2016).

7. Krammer, B. Vascular effects of photodynamic therapy. Anticancer research 21, 4271-4277 (2001).

8. Maeding, N., Verwanger, T. \& Krammer, B. Boosting tumor-specific immunity using PDT. Cancers 8, 91 (2016).

9. Kawczyk-Krupka, A. et al. Influence of ALA-mediated photodynamic therapy on secretion of interleukins 6,8 and 10 by colon cancer cells in vitro. Photodiagnosis and photodynamic therapy 22, 137-139 (2018). 
10. Dąbrowski, J. M. In Advances in Inorganic Chemistry Vol. 70 343-394 (Elsevier, 2017).

11. Dąbrowski, J. M. et al. Engineering of relevant photodynamic processes through structural modifications of metallotetrapyrrolic photosensitizers. Coordination Chemistry Reviews 325, 67-101 (2016).

12. Pucelik, B., Gürol, I., Ahsen, V., Dumoulin, F. \& Dąbrowski, J. M. Fluorination of phthalocyanine substituents: Improved photoproperties and enhanced photodynamic efficacy after optimal micellar formulations. European journal of medicinal chemistry 124, 284-298 (2016).

13. Berlanda, J., Kiesslich, T., Engelhardt, V., Krammer, B. \& Plaetzer, K. Comparative in vitro study on the characteristics of different photosensitizers employed in PDT. Journal of Photochemistry and Photobiology B: Biology 100, 173-180 (2010).

14. Cecic, I., Serrano, K., Gyongyossy-Issa, M. \& Korbelik, M. Cancer Lett. 225, 215-223 (2005).

15. Wachowska, M. et al. 5-Aza-2'-deoxycytidine potentiates antitumour immune response induced by photodynamic therapy. European Journal of Cancer 50, 1370-1381, https://doi.org/10.1016/j.ejca.2014.01.017 (2014).

16. Lisnjak, I., Kutsenok, V., Polyschuk, L., Gorobets, O. \& Gamaleia, N. Effect of photodynamic therapy on tumor angiogenesis and metastasis in mice bearing Lewis lung carcinoma. Exp Oncol 27, 333-335 (2005).

17. Allison, R., Moghissi, K., Downie, G. \& Dixon, K. Photodynamic therapy (PDT) for lung cancer. Photodiagnosis and photodynamic therapy 8, 231-239 (2011).

18. Loewen, G. M., Pandey, R., Bellnier, D., Henderson, B. \& Dougherty, T. Endobronchial photodynamic therapy for lung cancer. Lasers in surgery and medicine 38, 364-370 (2006).

19. Chen, B., Pogue, B. W., Hoopes, P. J. \& Hasan, T. Vascular and cellular targeting for photodynamic therapy. Critical Reviews ${ }^{\mathrm{TM}}$ in Eukaryotic Gene Expression 16 (2006).

20. Sirotkina, M. et al. Photodynamic therapy monitoring with optical coherence angiography. Scientific reports 7, 41506 (2017).

21. Zhang, Q. et al. Hypericin-photodynamic therapy induces human umbilical vein endothelial cell apoptosis. Scientific reports $\mathbf{5}$, 18398 (2015)

22. Ferrario, A. et al. Antiangiogenic treatment enhances photodynamic therapy responsiveness in a mouse mammary carcinoma. Cancer research 60, 4066-4069 (2000).

23. Kawczyk-Krupka, A. et al. ALA-induced photodynamic effect on vitality, apoptosis, and secretion of vascular endothelial growth factor (VEGF) by colon cancer cells in normoxic environment in vitro. Photodiagnosis and photodynamic therapy 13, 308-315 (2016).

24. Kawczyk-Krupka, A. et al. Secretion of the angiogenic factor VEGF after photodynamic therapy with ALA under hypoxia-like conditions in colon cancer cells. Photodiagnosis and photodynamic therapy 21, 16-18 (2018)

25. Yip, C., Blower, P. J., Goh, V., Landau, D. B. \& Cook, G. J. Molecular imaging of hypoxia in non-small-cell lung cancer. European journal of nuclear medicine and molecular imaging 42, 956-976 (2015).

26. Hockel, M. \& Vaupel, P. Tumor hypoxia: definitions and current clinical, biologic, and molecular aspects. Journal of the National Cancer Institute 93, 266-276 (2001).

27. Tang, X. et al. Overcome the limitation of hypoxia against photodynamic therapy to treat cancer cells by using perfluorocarbon nanodroplet for photosensitizer delivery. Biochemical and biophysical research communications 487, 483-487 (2017).

28. Henderson, B. W. \& Fingar, V. H. Relationship of tumor hypoxia and response to photodynamic treatment in an experimental mouse tumor. Cancer research 47, 3110-3114 (1987).

29. Tong, X. et al. Monitoring Tumor Hypoxia Using 18 F-FMISO PET and Pharmacokinetics Modeling after Photodynamic Therapy. Scientific reports 6, 31551 (2016).

30. Cheng, Y. et al. Perfluorocarbon nanoparticles enhance reactive oxygen levels and tumour growth inhibition in photodynamic therapy. Nature communications 6, 8785 (2015).

31. Krzykawska-Serda, M. et al. The role of strong hypoxia in tumors after treatment in the outcome of bacteriochlorin-based photodynamic therapy. Free Radical Biology and Medicine 73, 239-251 (2014).

32. Elas, M. et al. Electron paramagnetic resonance oxygen images correlate spatially and quantitatively with Oxylite oxygen measurements. Clinical Cancer Research 12, 4209-4217 (2006).

33. Elas, M., Ichikawa, K. \& Halpern, H. J. Oxidative stress imaging in live animals with techniques based on electron paramagnetic resonance. Radiation research 177, 514-523 (2012).

34. Elas, M. et al. Quantitative tumor oxymetric images from $4 \mathrm{D}$ electron paramagnetic resonance imaging (EPRI): Methodology and comparison with blood oxygen level-dependent (BOLD) MRI. Magnetic resonance in medicine 49, 682-691 (2003).

35. Bratasz, A. et al. In vivo imaging of changes in tumor oxygenation during growth and after treatment. Magnetic resonance in medicine 57, 950-959 (2007).

36. Elas, M. et al. Where it's at really matters: in situ in vivo vascular endothelial growth factor spatially correlates with electron paramagnetic resonance pO 2 images in tumors of living mice. Molecular Imaging and Biology 13, 1107-1113 (2011).

37. Gross, S., Gilead, A., Scherz, A., Neeman, M. \& Salomon, Y. Monitoring photodynamic therapy of solid tumors online by BOLDcontrast MRI. Nature medicine 9,1327 (2003).

38. Kim, A. et al. An Implantable Ultrasonically-powered Micro-Light-source ( $\mu$ Light) for photodynamic therapy. Scientific reports 9 , 1395 (2019).

39. Amirshaghaghi, A. et al. Chlorin e6-Coated Superparamagnetic Iron Oxide Nanoparticle (SPION) Nanoclusters as a Theranostic Agent for Dual-Mode Imaging and Photodynamic Therapy. Scientific reports 9, 2613 (2019).

40. Yin, T. et al. Superparamagnetic Fe 3O 4-PEG 2K-FA@ Ce6 nanoprobes for in vivo dual-mode imaging and targeted photodynamic therapy. Scientific reports 6, 36187 (2016).

41. Zhang, H. et al. Fluorescence and magnetic resonance dual-modality imaging-guided photothermal and photodynamic dualtherapy with magnetic porphyrin-metal organic framework nanocomposites. Scientific reports 7, 44153 (2017).

42. Ai, F. et al. A core-shell-shell nanoplatform upconverting near-infrared light at $808 \mathrm{~nm}$ for luminescence imaging and photodynamic therapy of cancer. Scientific reports 5, 10785 (2015).

43. Cheng, J. C.-H. et al. Early detection of Lewis lung carcinoma tumor control by irradiation using diffusion-weighted and dynamic contrast-enhanced MRI. PloS one 8, e62762 (2013).

44. Enomoto, A. et al. Four-channel surface coil array for 300-MHz pulsed EPR imaging: Proof-of-concept experiments. Magnetic resonance in medicine $\mathbf{7 1}, 853-858$ (2014).

45. Elas, M. et al. EPR oxygen images predict tumor control by a 50\% tumor control radiation dose. Cancer research 73, 5328-5335 (2013).

46. Rocha, L., Schaberle, F., Dąbrowski, J., Simões, S. \& Arnaut, L. Intravenous single-dose toxicity of redaporfin-based photodynamic therapy in rodents. International journal of molecular sciences 16, 29236-29249 (2015).

47. Luz, A. F., Pucelik, B., Pereira, M. M., Dąbrowski, J. M. \& Arnaut, L. G. Translating phototherapeutic indices from in vitro to in vivo photodynamic therapy with bacteriochlorins. Lasers in surgery and medicine 50, 451-459 (2018).

48. Pucelik, B., Arnaut, L. G., Stochel, G. \& Dabrowski, J. M. Design of Pluronic-based formulation for enhanced redaporfinphotodynamic therapy against pigmented melanoma. ACS applied materials ef interfaces 8, 22039-22055 (2016).

49. Liu, H. et al. Photothermal therapy of Lewis lung carcinoma in mice using gold nanoshells on carboxylated polystyrene spheres. Nanotechnology 19, 455101 (2008).

50. Kellar, A., Egan, C. \& Morris, D. Preclinical murine models for lung cancer: clinical trial applications. BioMed research international 2015 (2015). 
51. Allport, J. R. \& Weissleder, R. Murine Lewis lung carcinoma-derived endothelium expresses markers of endothelial activation and requires tumor-specific extracellular matrix in vitro. Neoplasia 5, 205-217 (2003).

52. Soriano, J. et al. Cell death mechanisms in tumoral and non-tumoral human cell lines triggered by photodynamic treatments: apoptosis, necrosis and parthanatos. Scientific reports 7, 41340 (2017).

53. Castano, A. P., Demidova, T. N. \& Hamblin, M. R. Mechanisms in photodynamic therapy: part one-photosensitizers, photochemistry and cellular localization. Photodiagnosis and photodynamic therapy 1, 279-293 (2004).

54. Chen, B., Pogue, B. W., Hoopes, P. J. \& Hasan, T. Combining vascular and cellular targeting regimes enhances the efficacy of photodynamic therapy. Int. J. Rad. Oncol. Biol. Phys. 61, 1216-1226 (2005).

55. Azzouzi, A.-R., Lebdai, S., Benzaghou, F. \& Stief, C. Vascular-targeted photodynamic therapy with TOOKAD $\left({ }^{\circledR}\right)$ Soluble in localized prostate cancer: standardization of the procedure. World Journal of Urology 33, 937-944, https://doi.org/10.1007/s00345-015-1535-2 (2015).

56. Azzouzi, A. R. et al. TOOKAD $\left({ }^{\circledR}\right)$ Soluble focal therapy: pooled analysis of three phase II studies assessing the minimally invasive ablation of localized prostate cancer. World Journal of Urology 33, 945-953, https://doi.org/10.1007/s00345-015-1505-8 (2015).

57. Dąbrowski, J. M., Arnaut, L. G., Pereira, M. M., Urbańska, K. \& Stochel, G. Improved biodistribution, pharmacokinetics and photodynamic efficacy using a new photostable sulfonamide bacteriochlorin. MedChemComm 3, 502-505 (2012).

58. Dąbrowski, J. M. et al. Biodistribution and photodynamic efficacy of a water-soluble, stable, halogenated bacteriochlorin against melanoma. ChemMedChem 6, 465-475 (2011).

59. Vakrat-Haglili, Y. et al. The Microenvironment Effect on the Generation of Reactive Oxygen Species by Pd-Bacteriopheophorbide. J. Am. Chem. Soc. 127, 6487-6497 (2005).

60. Chen, B., Roskams, T. \& de Witte, P. A. Antivascular tumor eradication by hypericin-mediated photodynamic therapy. Photochemistry and photobiology 76, 509-513 (2002).

61. Yu, G. et al. Noninvasive monitoring of murine tumor blood flow during and after photodynamic therapy provides early assessment of therapeutic efficacy. Clinical cancer research 11, 3543-3552 (2005).

62. Suzuki, M. et al. Neuroprotective response after photodynamic therapy: role of vascular endothelial growth factor. Journal of neuroinflammation 8, 176 (2011).

63. Saavedra, R., Rocha, L. B., Dąbrowski, J. M. \& Arnaut, L. G. Modulation of biodistribution, pharmacokinetics, and photosensitivity with the delivery vehicle of a bacteriochlorin photosensitizer for photodynamic therapy. ChemMedChem 9, 390-398, https://doi. org/10.1002/cmdc.201300449 (2014).

64. Gollmer, A. et al. Singlet Oxygen Sensor Green ${ }^{\circledR}$ : photochemical behavior in solution and in a mammalian cell. Photochemistry and photobiology 87, 671-679 (2011).

65. Hatz, S., Lambert, J. D. \& Ogilby, P. R. Measuring the lifetime of singlet oxygen in a single cell: addressing the issue of cell viability. Photochemical \& Photobiological Sciences 6, 1106-1116 (2007).

\section{Acknowledgements}

The work was supported by Sonata Bis grant no 2016/22/E/NZ7/00420 (National Science Center, NCN) given to JMD. BP tkanks Foundation for Polish Science for START 071.2019 programme. MK thanks Ministry of Science and Higher Education of Poland for Diamentowy Grant no 0062/DIA/2014/43. Some of the research was carried out with equipment purchased with the financial support of the European Regional Development Fund in the framework of the Polish Innovation Economy Operational Program (contract no. POIG.02.01.00-12-167/08, project Malopolska Centre of Biotechnology). The authors thank L.G. Arnaut for valuable discussion and Luzitin S.A. for providing redaporfin.

\section{Author Contributions}

J.M.D. and M.E. conceived the experiments, M.K., B.P., M.G. and J.M.D. conducted the experiments, M.K., B.P., M.G., M.E. and J.M.D. analyzed the results. All authors took part in writing the manuscript.

\section{Additional Information}

Competing Interests: The authors declare no competing interests.

Publisher's note: Springer Nature remains neutral with regard to jurisdictional claims in published maps and institutional affiliations.

Open Access This article is licensed under a Creative Commons Attribution 4.0 International License, which permits use, sharing, adaptation, distribution and reproduction in any medium or format, as long as you give appropriate credit to the original author(s) and the source, provide a link to the Creative Commons license, and indicate if changes were made. The images or other third party material in this article are included in the article's Creative Commons license, unless indicated otherwise in a credit line to the material. If material is not included in the article's Creative Commons license and your intended use is not permitted by statutory regulation or exceeds the permitted use, you will need to obtain permission directly from the copyright holder. To view a copy of this license, visit http://creativecommons.org/licenses/by/4.0/.

(C) The Author(s) 2019 